\title{
Autonomous Control of Multi Speed Split Unit Air Conditioning for Space Load Response
}

\author{
Wasan Asaad Jwad ${ }^{1}$, Ali Lateef Tarish ${ }^{2}$ \\ \{E-mail addresses wasan.alansary@stu.edu.iq ${ }^{1}$, alialali@stu.edu.iq $\left.{ }^{2}\right\}$ \\ Control and Automation Eng. Dept., Eng.Technical College-Basra, Southern Technical University, \\ Basra, Iraq ${ }^{1}$ \\ Thermal Mechanics Eng. Dept., Eng.Technical College-Basra, Southern Technical University, Basra, \\ Iraq $^{2}$
}

\begin{abstract}
Succeeding comfort conditions in hot climates region with minimum power consumption is the important requisite in designing the air conditioning system such as split unit air conditioning (SUAC). Under Iraqi conditions, the current study compared the energy consumption of SUAC in two classrooms at Southern Technical University/Engineering Technical College-Basra (STU/TCB). Additionally, this paper developed an autonomous cooperative controller for sensing changes in dynamic space load and auto response of a variable speed compressor over a 12-hour period. The first classroom has a single-speed SUAC compressor, while the second classroom has a variable-speed SUAC compressor with a total capacity of 6 Ton. The results show that in June, the largest amount of energy saved was $51.5 \%$ at $7 \mathrm{AM}$, while the least amount of energy saved was $10.9 \%$ at 14 PM. SUAC with autonomous controller was discovered to be the highest control unit with less energy utilized than other SUACs, achieving a value of $24.8 \%$ energy savings. The split unit control (SUC) could result in a significant reduction in SUAC compressor power in class 2 at seasonal energy efficiency rating (SEER) levels 8 or 20 , resulting in a $75 \%$ reduction in operating costs throughout the year.
\end{abstract}

Keywords:Air conditioning application; Split unit; multi speed compressor; autonomous control; energy saving.

\section{Introduction}

In Iraqi cities, split unit air conditioners (SUAC) are commonly used in both residential and commercial buildings. The SUAC working with conventional vapor compression refrigeration cycle [1]. The air conditioning appliance accounts for $70 \%$ of the energy consumed in the building. The significant replenishing demand on the electricity systems in Iraq during the summer contributes mainly to peak loads, due to the warm weather in Iraq [2]. Moreover, the costs of power generation are raised because of a high renewal load, but overall network efficiency is also lowered [3]. In recent years, SUAC single speed compressors in home and industrial buildings worldwide have been replaced by SUAC variable speed compressors that have lower electricity consumption. The SUAC variable speed compressor operates under varying frequencies and includes a variety of refrigeration capabilities to more rapidly and efficiently satisfying altering comfort requirements. Two ways are existed to control compressor 
speed in SUAC variable speed compressors. The first have been controlled manually, but the other one senses the required temperature of the condition space and change speed dependently. Inside design condition cannot be achieved using these ways due to the outdoor design condition in Iraq reach to $50 \mathrm{C}$ [2]. Under this viewpoint, a need for a more responsible control system is raised. A multi-Agent system (MAS) is one of more suitable proposed control strategy for such systems, due to its properties such as intelligence, autonomous, modularity and social ability [4]. MAS consists of a society of entities inhabiting an environment, interacting with their environment and cooperating with each other in a distributed fashion to achieve whole delegated task [5].

The previous studies has looked at the usage of a multi-speed compressor SUAC, building energy demand, and HVAC control methods for the purpose of minimize high energy demand in residential and commercial buildings. The electrical expansion valve controllers with variable speed compactors were suggested by Alaa and Ahmed [6]. The results revealed that the use of the right control technique can have a substantial impact instead of the kind of controller on the performance coefficient (COP) and system stability. Moaomao \& et al.[7] were using the probability relation test technique to investigate variable speed SUAC in order to get the most acceptable energy performance model. Test results show that COP and capacity estimates for the conventional multi speed SUAC can be efficiently selected with moderate complexity and satisfactory exactness using the model evaluation technique. Jaehun Lim et al. [8] experimentally evaluated the saving energy of the inverter SUAC to assess the constant-speed SUAC in a Korean environment with four various climates and a warm temperatures in Saudi Arabia during the year. The inverter air conditioner's energy savings were primarily determined by variations in temperature and cooling demand over the course of a day or season. The machine learning technique was utilized for variable speed SUAC, according to Zhijie Chen et al.[9]. To create simulation data under diverse settings of distinct situations, a machine learning augmented inverse modeling approach is given. The clustering technique is used to categorize the training data while keeping the weights of different conditions suitably balanced. Amr and Kayed [10] studied the thermal performance of an SUAC with a variable speed compressor in the environment. According to the results, increasing the condenser input air temperature by 7 ${ }^{\circ} \mathrm{c}$ raised power consumption by $18 \%$ while lowering the COP by $15 \%$. The multi agent and other control systems were investigated by the researchers in determining the most effective control and energy savings for the air conditioning system [11-14].

According to previous research, the SUAC single speed compressors switch on or off when the thermostat indicates that the condition space temperature is higher or lower than the required set temperature. It is important to note that the SUAC single-speed compressors in Iraq city will be running 24 hours a day for the next three months (June, July and August). Furthermore, the compressor power and electric demand are both high due to the controlled SUAC identification is limited. Up to author's knowledge, investigating the relationship between space load and multi-speed SUAC has not been yet achieved under Iraqi conditions.

In this work, multi-speed compressor SUAC is operated with a control autonomous reactive agent to optimize compressor speed with space load. Over the day, there is a significant gap between space load demand and SUAC capacity, where space load fluctuating throughout the day but SUAC capacity remaining constant, resulting in energy customer fixed during the day. In addition, the SUAC variable speed compressor operates at a set speed without consideration to the space load in the condition space. This study intends to propose an autonomous competent control model for multi speed SUAC that can work depending on a wide variety of space load and is appropriate for using in STU/TCB during the $12 \mathrm{hr}$. This allows the SUAC to obtain the best comfort temperature while using minimal energy. As a result, a new 
autonomous cooperative controller for sensing changes in dynamic space load and auto response of a variable speed compressor has been developed. A comparison of energy savings between a single-speed SUAC compressor and a multi-speed SUAC compressor is presented. The SEER was used to evaluate energy input to compressor based on the examined SUAC to provide assessment of SUAC efficiency and electric cost.

\section{Multi Speed SUAC Description}

Figure 1 depicts the SUAC schematic diagram. The SUAC is in the process of completing a vapor compression refrigeration cycle. The heat from the conditioned space in the classroom is absorbed by the evaporator. The multi-speed compressor is then used to increase the refrigerant pressure from evaporator to condenser pressure, with heat being rejected to the environment in the condenser and pressure being reduced from condenser to evaporator temperature in the expansion device. Multi-speed compressors use an inverter to alter the motor's working speed by speeding up or slowing it down. The compressor is powered with a set voltage by the inverter, which saves energy.

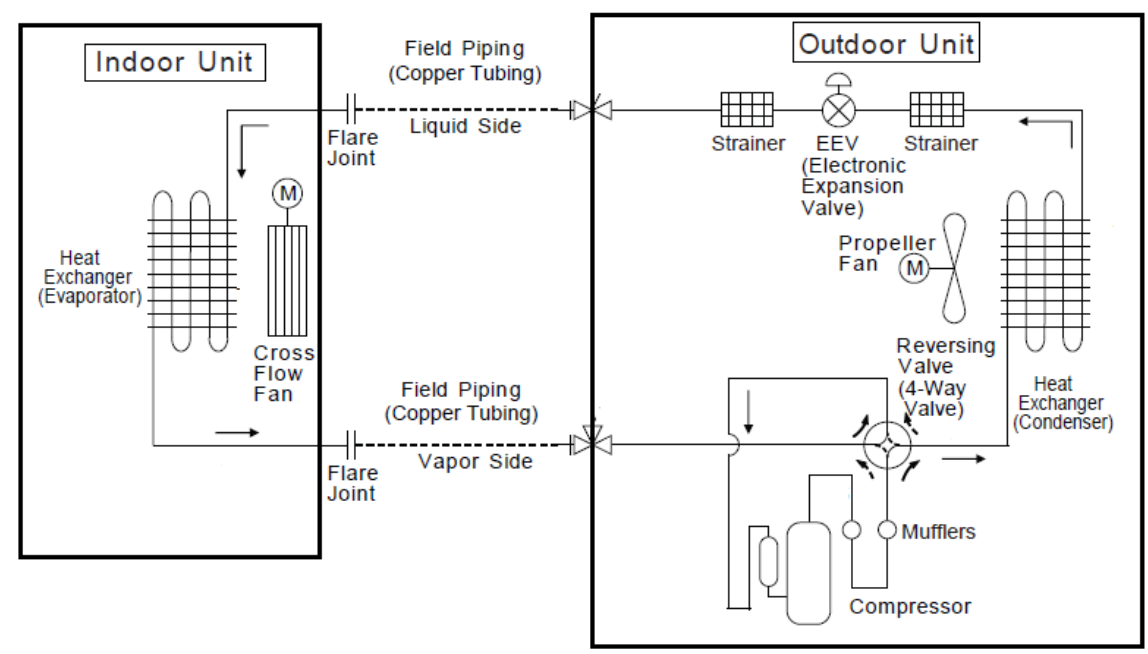

Fig. 1. SUAC diagram.

\section{Methodology}

The autonomous cooperative controller's purpose is to identify changes in dynamic space load across a large working range (three month). To achieve the auto response of a variable speed compressor SUAC, the SUAC is operated while the compressor speed and cooling load are varied in this study. The space load is altered every hour, with the hypothesis that the space load will not change significantly in that time. During a 12-hour period, the space load for two classrooms (lecture theatre) is determined (8 AM to $8 \mathrm{PM}$ ). A single-speed SUAC compressor with a total capacity of 6 Ton is in the first classroom, while a variable-speed SUAC compressor with a total cooling capacity of 6 Ton is in the second. The dynamic space load is input into two SUACs and the suitable speed compressor is determined by negotiation between them. The method and procedures for the current work will be described in the following sections. 


\subsection{Space Load Estimation}

Solar radiation, conduction load, ventilation/infiltration load, and interior load are the four components that make up the classroom space load. The overall space load is estimated by calculating all of these loads separately and summing all together. The CLTD technique is used to calculate the cooling load for the classroom in the TCB. Figure 2(a) shows the case study TCB ground building, whereas Figure 2(b) depicts two classrooms with SUAC. The SUAC with constant capacity is used in the first class, whereas the SUAC with SUC is used in the second class. The heat transmission during wall, roof, floor, door and glass as the following [15]:

$$
\mathrm{Q}=\mathrm{UACLTD}_{\mathrm{C}}
$$

$$
\operatorname{CLTD}_{\mathrm{C}}=\left[(\mathrm{CLTD}+\mathrm{LM}) \mathrm{k}+\left(25.5-\mathrm{T}_{\mathrm{r}}\right)+\left(\mathrm{T}_{\mathrm{o}}-29.4\right)\right] \mathrm{f}
$$

Solar heat gain:

$$
Q_{s}=\text { A.SC.SH.CLF }
$$

The equipment load in the classroom:

$$
Q_{e}=\text { P.CLF }
$$

The sensible and latent heat of student [16]:

$$
\begin{gathered}
Q_{\text {so }}=\text { N. G } \cdot C_{s} \cdot C_{\text {s }} \\
Q_{\text {lo }}=N \cdot G_{1}
\end{gathered}
$$

The ventilation and infestation [16]:

$$
\mathrm{Q}_{\mathrm{v}}=\mathrm{N} \text {. (liters/ sec per person) }
$$

$$
Q_{i}=V \cdot A C H / 3600
$$

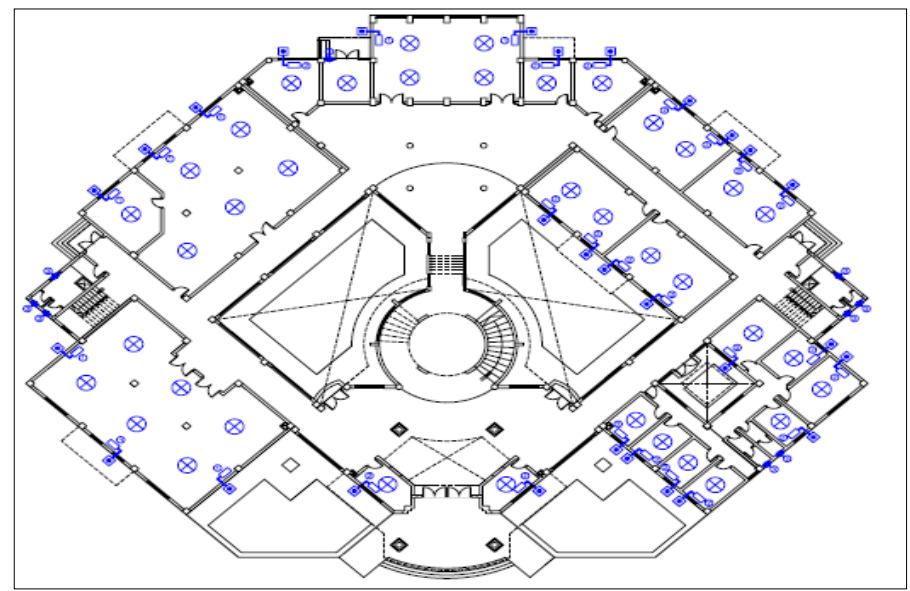

Fig. 2 (a). TCB ground building. 


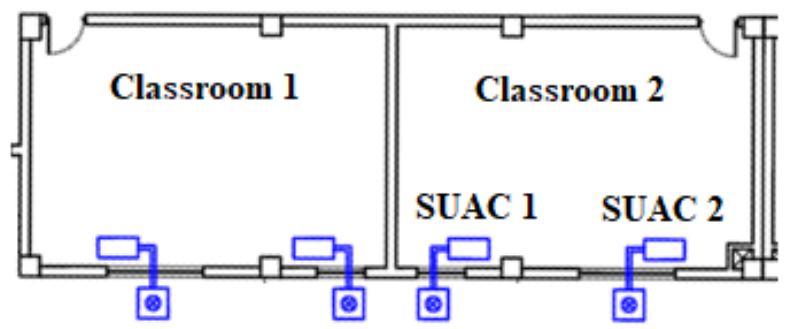

Fig. 2 (b). Case study classrooms.

\subsection{SUAC Control Behavior}

Aggregating the split unit's sub-activities should yield the overall behavior of an SUAC system. Each unit inhabited in environment and has the ability to interact with it. Singular one adheres to a general strategy that explains how to solve the problem at hand. The proposed work's strategy incorporates reactive response. The system has the ability to solve problems autonomously, which implies it can govern its internal states and make decisions on how to operate in its surroundings without the need for human intervention. Making decision will be as a reactive action that described as a request/reply wave of interactions among system units to take an action that affect environment and solve the current state.

\subsection{Unit Control Architecture}

Split unit control (SUC) is the given name to the proposed system controllers. The SUC architecture shows how a structure can be divided into a series of modules to handle certain tasks, as well as how these components interact, and how information and control travel between modules to determine what actions should be taken [17-19]. The general structure of the SUC is modular, comprises of seven modules activated separately at moment to perform the dedicated duty at the time. These modules connected together and centered around an essential centralized one called the Decision-Making module which responsible for taking decision depending on related rules and databases. The SUC modules comprises three essential modules which are: Input module for entering the information from environment.

The second module is the Decision-Making Module, the key module where all decisionmaking processes are based on the overall strategy for completing the targeted tasks. The third critical module is the Action module, which carries out the decisions made by the decision making module and transmitted as reactions to the environment. In addition, there are other supported modules like the Data Base Update (DB Update) module is in capable of updating data in the database. Reactive Knowledge Base (Reactive KB) module which hosts all rules needed to make decision. Strategy selection module which has two paths to select. And finally, the Negotiation Module that is triggered when there is a need to interact with other SUC to solve problem (see figure 3 ). 


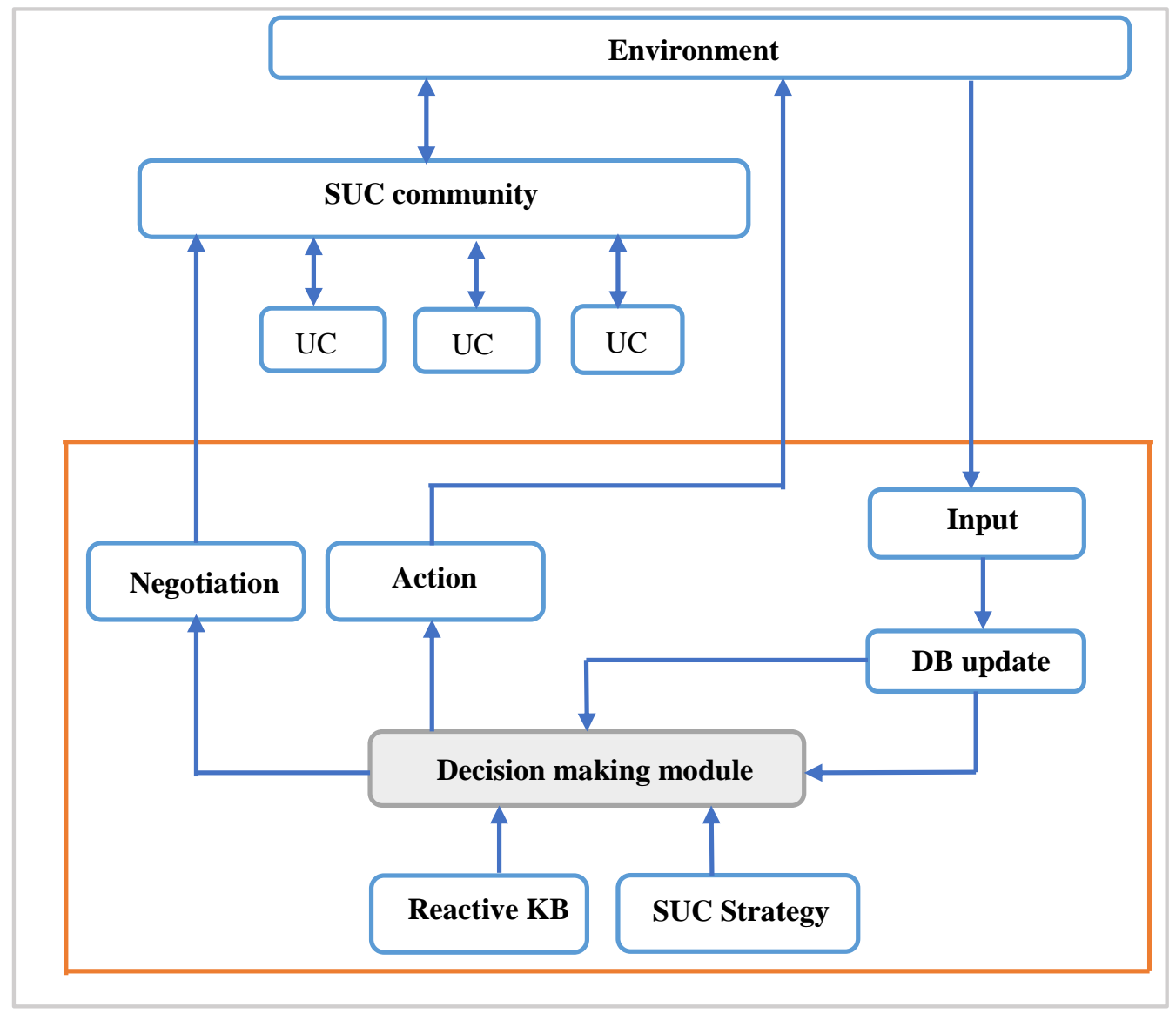

Fig. 3. SUC architecture.

\section{Results and Discussion}

The purpose of design a proposed system is to manage the compressor speed of SUAC in classroom, where this speed is suitable with space load. There are two SUAC in classroom, each one has SUC to manage its speed per hour. The main task that dedicated to controller is to reduce compressor speed in hour therefor the investigating of energy saving could be achieved. The total space load that set as the input parameter of the model has been considered by decision making module which in turn attempts to take a decision as an action about compressor speed. Decision making module determines the strategy path according to the entered load, where there are two paths: reactive reaction means determining the suitable speed in the limited range as speed1, speed2, or speed3. While the other strategy path is urged when the total input load is over the limited range in SUC, so there is a need to negotiate with a fellow SUC to solve the problem and accomplish the delegated task. The other important module is the reactive knowledge base module who stores the rules that is relied by decision making module to change compressor speed under conditions. 
For example, if the total space load in the range of speed 1 or 2 the compressor speed will be work in speed1 or 2, otherwise if the range in speed3 then the SUC1 will take half of load as input and test in which range of speed it is, then send the remaining load to other partner SUC who in turn tries to take it role to solve problem in the same strategy of SUC1.

\subsection{Space load}

During three months, the space load calculation for two classrooms is changed every hour from $10.2 \mathrm{~kW}$ to $19.5 \mathrm{~kW}$. Due to solar heat gain, heat transformation, and student activity, the space load varies from 8 AM to 8 PM. Figure 4 depicts the space load on the first day from the mouth in June, July, and August. The space loads show a significant variation in hour 13 (see Figure 4) attributed to the reason that the classroom is empty at this time which lead to reduce the internal loads.

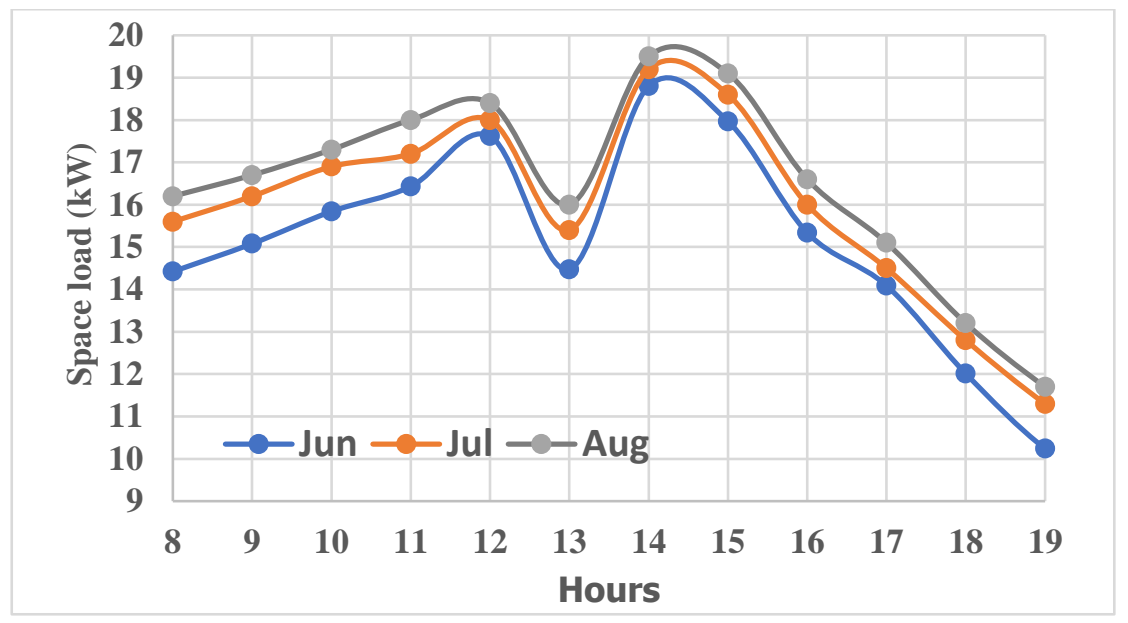

Fig. 4. Space load variation over a 12 -hour period.

\subsection{Negotiation of SUC}

Two split units in studying room in TCB are utilized to challenge the SUAC ability to manage such compressor speed. This is fortified with calculated total loads starting from 8 AM until $8 \mathrm{PM}$ as show in the Table 1. Other input parameter is the total capacity which is calculated by summation the SUC1 and SUC2' capacities, in case study it equals 6 Ton $(21.096 \mathrm{~kW})$. The decision making module utilizes the input information to take decision depending on rules stored in Reactive KB module. To do so, in hour $7 \mathrm{PM}$ in June month, the space load is $14.42 \mathrm{~kW}$, SUC1 is triggered to start work, the capacity of SUC1 in speed1 or 2 cannot cover this value, so the independent strategy is by dividing load and trying to change speed into speed 1 or 2 ranges autonomously. Then send packet with the remaining load to fellow SUC in classroom to start negotiation with him. SUC2 receives a packet requesting to do a task from SUC1 to solve the problem. SUC2 is working with a half of load in same strategy of SUC1. Check if speed1, 2 or 3 can cover the remaining load then send reply packet to SUC1 with the result of achievement job. In hour 8 AM, SUC1 changes speed to speed2, and SUC2 works in speed2 
too, so both SUCs do not work in full power and save $31 \%$ of energy in this hour (see Figure 5). Table 1 shows the behavior of SUCs in 12 hours in three days in June, July and August, where selected speeds each hour and the percentage of saved energy with the proposed system. The maximum value of save energy in June is $51.5 \%$ in hour 7 AM, because solar energy decreased. While the minimum value is $10.9 \%$ in hour 14 due to full load caused by maximum solar energy in Basrah city, and other space load. As shown in Table 1 in hour 15 the space load in June day is $17.97 \mathrm{~kW}$, in July is $18.6 \mathrm{~kW}$, and in August is $19 \mathrm{~kW}$. In June and July, both SUCs work with speed 2 and cooperate to reduce lost energy. However, in August SUC1 work with speed 2 while SUC2 work with speed3 to cover the load and save energy as possible.

Table 1. Compressor speed response for space load for three months.

\begin{tabular}{|c|c|c|c|c|c|c|c|c|c|c|c|c|}
\hline \multicolumn{13}{|c|}{ 01-Jun } \\
\hline Hours & 8 & 9 & 10 & 11 & 12 & 13 & 14 & 15 & 16 & 17 & 18 & 19 \\
\hline $\begin{array}{l}\text { Space } \\
\text { Load (kW) }\end{array}$ & 14.42 & 15.08 & 15.84 & 16.43 & 17.62 & 14.47 & 18.8 & 17.97 & 15.34 & 14.09 & 12.01 & 10.24 \\
\hline $\begin{array}{l}\text { Compospeed } \\
\text { SUCl }\end{array}$ & 2 & 2 & 2 & 2 & 2 & 2 & 2 & 2 & 2 & 2 & 2 & 1 \\
\hline $\begin{array}{l}\text { Comp Speed } \\
\text { SUC2 }\end{array}$ & 2 & 2 & 2 & 2 & 2 & 2 & 2 & 2 & 2 & 2 & 2 & 1 \\
\hline Save Energy \% & 31.65 & 28.52 & 24.91 & 22.12 & 16.48 & 31.41 & 10.88 & 14.82 & 27.28 & 33.21 & 43.07 & 51.46 \\
\hline \multicolumn{13}{|c|}{ 01-Jul } \\
\hline Hours & 8 & 9 & 10 & 11 & 12 & 13 & 14 & 15 & 16 & 17 & 18 & 19 \\
\hline $\begin{array}{l}\text { Space } \\
\text { Load (kW) }\end{array}$ & 15.6 & 16.2 & 16.9 & 17.2 & 18 & 15.4 & 19.2 & 18.6 & 16 & 14.5 & 12.08 & 11.03 \\
\hline $\begin{array}{l}\text { Comp_Speed } \\
\text { SUCl }\end{array}$ & 2 & 2 & 2 & 2 & 2 & 2 & 2 & 2 & 2 & 2 & 2 & 1 \\
\hline $\begin{array}{l}\text { Comp_Speed } \\
\text { SUC2 }\end{array}$ & 2 & 2 & 2 & 2 & 2 & 2 & 3 & 2 & 2 & 2 & 2 & 2 \\
\hline Save Energy \% & 26.10 & 23.20 & 19.90 & 18.50 & 14.70 & 27 & 9 & 11.80 & 24.20 & 31.30 & 42.70 & 47.70 \\
\hline \multicolumn{13}{|c|}{ 01-Aug } \\
\hline Hours & 8 & 9 & 10 & 11 & 12 & 13 & 14 & 15 & 16 & 17 & 18 & 19 \\
\hline $\begin{array}{l}\text { Space } \\
\text { Load (kW) }\end{array}$ & 16.2 & 16.7 & 17.3 & 18 & 18.4 & 16 & 19.5 & 19.1 & 16.6 & 15.1 & 13.2 & 11.7 \\
\hline $\begin{array}{l}\text { Comp.Speed } \\
\text { SUCl }\end{array}$ & 2 & 2 & 2 & 2 & 2 & 2 & 2 & 2 & 2 & 2 & 2 & 1 \\
\hline $\begin{array}{l}\text { Comp Speed } \\
\text { SUC2 }\end{array}$ & 2 & 2 & 2 & 2 & 2 & 2 & 3 & 3 & 2 & 2 & 2 & 2 \\
\hline Save Energy \% & 23.20 & 20.80 & 18 & 14.70 & 12.80 & 24.20 & 7.60 & 9.50 & 21.30 & 28.40 & 37.40 & 44.50 \\
\hline
\end{tabular}

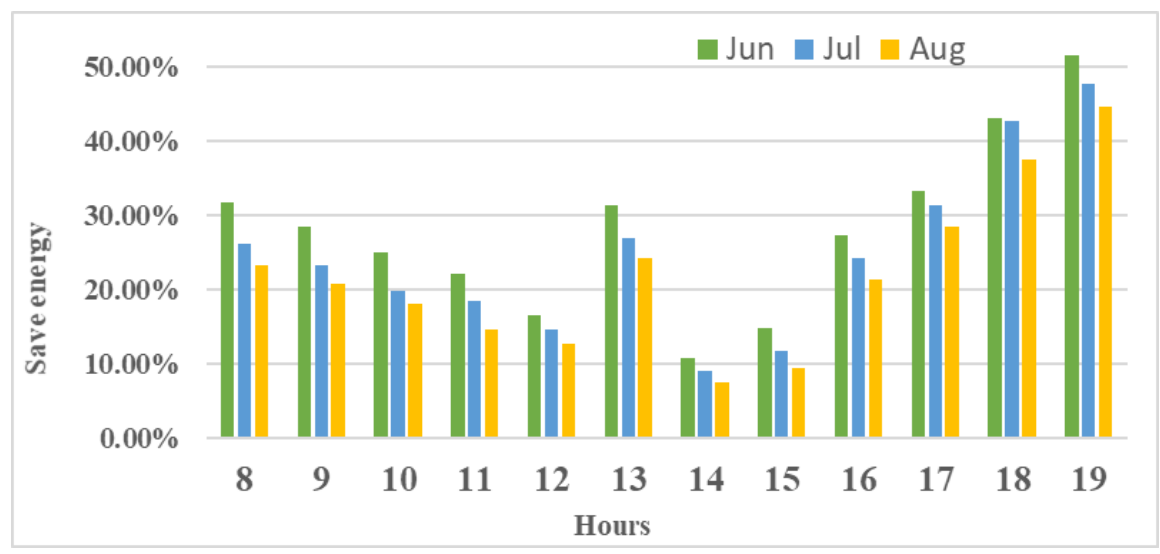

Fig. 5. Save energy for SUAC. 


\subsection{SUAC Efficiency}

The Seasonal Energy Efficiency Rating (SEER) evaluates SUAC efficiency, which is computed by dividing the refrigeration capacity for a standard cold period by the total electrical power input over the same time period [20]. For example, if your SUAC has a SEER rating of 20 , that is its maximum efficiency. The energy input to SUAC equal to capacity for year divide SEER. The results indicate that SUC could lead to significant reductions in SUAC compressor power in classroom 2 at constant SEER values (see Table2), resulting in reduced operating expenses throughout the year. This explains the observed decrease in energy input to compressor with constant capacity during the year.

Table 2. The SEER and annual running costs.

\begin{tabular}{|c|c|c|c|c|c|c|c|c|c|c|}
\hline SEER & $\begin{array}{l}\text { Capacity } \\
\text { SUAC i } \\
\text { (BTU/hr) }\end{array}$ & $\begin{array}{l}\text { Capacity } \\
\text { SUAC 2 } \\
\text { (BTU/hr) }\end{array}$ & $\begin{array}{c}\text { Total } \\
\text { capacity } \\
(\mathrm{BTU} / \mathrm{hr})\end{array}$ & $\begin{array}{c}\text { Operating } \\
\text { time } \\
12 \mathrm{hr} / \mathrm{day}\end{array}$ & $\begin{array}{c}\text { Operating } \\
\text { time } \\
\text { 200day/year }\end{array}$ & $\begin{array}{c}\text { Capacity } \\
\text { for year } \\
\text { BTU/year }\end{array}$ & $\begin{array}{c}\text { Energy } \\
\text { input } \\
\text { kW.hr/year }\end{array}$ & $\begin{array}{c}\text { Cost } \\
\text { S } \\
\mathrm{kW} . \mathrm{h} \\
\mathrm{r}\end{array}$ & $\begin{array}{l}\text { Cost } \\
\text { S/year }\end{array}$ & $\begin{array}{c}\text { Cost } \\
\text { IQD/year }\end{array}$ \\
\hline \multicolumn{11}{|c|}{$\begin{array}{l}\text { Lecture } \\
\text { theatre } 1\end{array}$} \\
\hline 8 & 36000 & 36000 & 72000 & 12 & 200 & 172800000 & 21600 & 0.1 & 2160 & 3240000 \\
\hline \multicolumn{11}{|c|}{$\begin{array}{l}\text { Lecture } \\
\text { theatre } 2\end{array}$} \\
\hline 8 & 36000 & 36000 & 72000 & 12 & 200 & 172800000 & 7200 & 0.1 & 540 & 810000 \\
\hline \multicolumn{11}{|c|}{$\begin{array}{l}\text { Lecture } \\
\text { theatre } 1\end{array}$} \\
\hline 20 & 36000 & 36000 & 72000 & 12 & 200 & 172800000 & 8640000 & 0.1 & 864 & 1296000 \\
\hline \multicolumn{11}{|c|}{$\begin{array}{l}\text { Lecture } \\
\text { theatre } 2\end{array}$} \\
\hline 20 & 36000 & 36000 & 72000 & 12 & 200 & 172800000 & 8640000 & 0.1 & 216 & 324000 \\
\hline
\end{tabular}

\section{Conclusions}

The proposed SUC's architecture is developed to control the SUAC's compressor speed in the classroom when that speed is adequate for loading space. The proposed system is selfcontained and requires no human interaction. The classroom space load is estimated for three months in Iraqi climates. The maximum space load is $17.97 \mathrm{~kW}$ in June, $18.6 \mathrm{~kW}$ in July, and $19 \mathrm{~kW}$ in August. In June the maximum saving power in hour $7 \mathrm{AM}$ was $51.5 \%$ due to a low in solar energy. The minimum amount of save energy is $10.9 \%$ at an hour 14 due to full solar heat loads. Both SUCs work with speed 2 in June and July and cooperate in reducing energy loss. SUC1 works with speed2 however in August, whereas SUC2 works with speed3 to cover the load and reduce energy. The multi speed SUAC with SUC was discovered to be the higher control unit with less energy used than other SUACs, in which the $24.8 \%$ energy saving value is achieved. The SUC could lead to a large decrease of the SUAC compressor power in class 2 at SEER levels 8 or 20 , with the result that the operating cost could be decreased by 75 percent throughout the year. The results indicated that the SUC architecture may be regarded a successful and efficient solution for multi-speed SUAC verification, and that it can be used in classroom applications at Southern Technical University/Engineering Technical College-Basra without requiring human interaction. 


\section{Nomenclature}

\begin{tabular}{|c|c|}
\hline Symbol & Definition \\
\hline $\mathbf{A}$ & Area $\left(\mathrm{m}^{2}\right)$ \\
\hline ACH & Air change per hour \\
\hline CLF & Cooling load factor [-] \\
\hline CLFs & Cooling load factor for occupants [-] \\
\hline CLTD & Cooling load temperature difference $\left({ }^{\circ} \mathrm{C}\right)$ \\
\hline CLTD $_{c}$ & Cooling load temperature difference correction $\left({ }^{\circ} \mathrm{C}\right)$ \\
\hline $\mathbf{f}$ & Attic fan factor [-] \\
\hline $\mathbf{G}_{\mathbf{l}}$ & Activity of occupants (latent) (W) \\
\hline $\mathbf{G}_{\mathbf{s}}$ & Activity of occupants (sensible) (W) \\
\hline $\mathbf{k}$ & Colour factor $[-]$ \\
\hline LM & Latitude month correction \\
\hline $\mathbf{N}$ & Number of occupants \\
\hline $\mathbf{Q}$ & Heat transmission $(\mathrm{kW})$ \\
\hline $\mathbf{P}$ & Power of equipment (W) \\
\hline$Q_{\mathbf{e}}$ & Equipment load $(\mathrm{kW})$ \\
\hline $\mathbf{Q}_{\mathbf{i}}$ & Infiltration load $\left(\mathrm{m}^{3} / \mathrm{sec}\right)$ \\
\hline Qlo & Latent occupant load $(\mathrm{kW})$ \\
\hline $\mathbf{Q}_{\mathrm{s}}$ & Solar heat gain $(\mathrm{kW})$ \\
\hline $\mathbf{Q}_{\text {so }}$ & Sensible occupant load $(\mathrm{kW})$ \\
\hline Qv & Ventilation load (liter/sec) \\
\hline SC & Shading coefficient [-] \\
\hline SH & Solar heat $\left(\mathrm{W} / \mathrm{m}^{2}\right)$ \\
\hline $\mathbf{T}_{\mathbf{0}}$ & Outside room temperature $\left({ }^{\circ} \mathrm{C}\right)$ \\
\hline $\mathbf{T}_{\mathbf{r}}$ & Inside room temperature $\left({ }^{\circ} \mathrm{C}\right)$ \\
\hline
\end{tabular}

\section{References}

[1] Tarish, A. L., et al. "Exergy and performance analyses of impact subcooling for vapor compression refrigeration system utilizing eco-friendly refrigerants." IOP Conference Series: Materials Science and Engineering. Vol. 997. No. 1. IOP Publishing, 2020. https://doi.org/10.1088/1757899X/997/1/012158

[2] Tarish, Ali Lateef, Mushtaq Talib Hamzah, and Wasan Assad Jwad. "Thermal and exergy analysis of optimal performance and refrigerant for an air conditioner split unit under different Iraq climatic conditions." Thermal Science and Engineering Progress 19 (2020): 100595. https://doi.org/10.1016/j.tsep.2020.100595

[3] Yoon, Ji Hoon, Ross Bladick, and Atila Novoselac. "Demand response for residential buildings based on dynamic price of electricity." Energy and Buildings 80 (2014): 531-541.

[4] Russell, Stuart, and Peter Norvig. "Artificial intelligence: a modern approach." (2002).

[5] Wooldridge, Michael. An introduction to multiagent systems. John wiley \& sons, 2009.

[6] Al-Badri, Alaa R., and Ahmed H. Al-Hassani. "A control method using adaptive setting of electronic expansion valve for water chiller systems equipped with variable speed compressors." International Journal of Refrigeration 119 (2020): 102-109.

[7] Hu, Maomao, Fu Xiao, and Howard Cheung. "Identification of simplified energy performance models of variable-speed air conditioners using likelihood ratio test method." Science and Technology for the Built Environment 26.1 (2020): 75-88.

[8] Lim, Jaehun, et al. "Feasibility study on variable-speed air conditioner under hot climate based on realscale experiment and energy simulation." Energies 12.8 (2019): 1489. 
[9] Chen, Zhijie, et al. "Machine learning enhanced inverse modeling method for variable speed air conditioning systems." International Journal of Refrigeration 118 (2020): 311-324.

[10] Elsayed, Amr Owes, and T. S. Kayed. "Dynamic performance analysis of inverter-driven split air conditioner." International Journal of Refrigeration 118 (2020): 443-452.

[11] Wang, Beibei, et al. "Consensus control strategy of an inverter air conditioning group for renewable energy integration based on the demand response." IET Renewable Power Generation 12.14 (2018): 1633-1639.

[12] Windham, Andrew Winsome. "A multi-agent decision process for controlling heating, ventilation, and air-conditioning systems." (2014).

[13] Lee, Dasheng, and Fu-Po Tsai. "Air conditioning energy saving from cloud-based artificial intelligence: Case study of a split-type air conditioner." Energies 13.8 (2020): 2001.

[14] Lork, Clement, et al. "An uncertainty-aware deep reinforcement learning framework for residential air conditioning energy management." Applied Energy 276 (2020): 115426.

[15] Nielsen, Peter Vilhelm, et al. "Indoor Environmental Modelling: Chapter 34 in ASHRAE Handbook, Fundamentals." ASERAE Handbook, Fundamentals. American Society of Heating, Refrigerating and Air-Conditioning Engineers, Inc., 2005.

[16] McQuiston, Faye C., Jerald D. Parker, and Jeffrey D. Spitler. Heating, ventilating, and air conditioning: analysis and design. John Wiley \& Sons, 2004.

[17] McArthur, Stephen DJ, and Euan M. Davidson. "Concepts and approaches in multi-agent systems for power applications." Proceedings of the 13th International Conference on, Intelligent Systems Application to Power Systems. IEEE, 2005.

[18] Sycara, Katia P. "Multiagent systems." AI magazine 19.2 (1998): 79-79.

[19] Wasan A.Jwad and gasim "A Probabilistic Finite State Machine based Residential Environment for Obligation Agent Development" The Third Southern University International Conference. Vol.6. P.164.

[20] Kim, Woohyun, and James E. Braun. "Evaluation of the impacts of refrigerant charge on air conditioner and heat pump performance." International journal of refrigeration 35.7 (2012): 18051814. 